\title{
SEGREGAÇÃO URBANA EM CIDADES PEQUENAS: ALGUMAS CONSIDERAÇÕES A PARTIR DAS ESCALAS INTRA E INTERURBANA
}

\section{Urban segregation in small towns: some considerations from intra and interurban scales}

\author{
Orlando Moreira Junior ${ }^{1}$
}

\section{RESUMO}

Este trabalho propõe problematizar a segregação urbana em cidades pequenas, pensando tanto em sua configuração intraurbana quanto na sua estrutura interurbana, estabelecendo um nexo entre pesquisas já efetuadas a respeito da temática e a realização de uma reflexão a partir de um estudo de caso nas cidades paulistas de Capão Bonito e Ribeirão Grande. Para tanto, a questão da habitação se sobressai, ao passo que a reprodução da moradia emerge como uma das facetas da segregação urbana em cidades pequenas, resultado dos (des) interesses dos atores que produzem o espaço, principalmente quando falamos da construção de conjuntos habitacionais para a população menos abastada.

Palavras-chave: cidades pequenas; segregação urbana; habitação.

\begin{abstract}
This article intends to discuss the urban segregation in small towns, both in their thinking about intra-urban setting and in its structure interurban, establishing a link between research already done on the topic and the realization of a reflection from a case study in the cities of Capão Bonito and Ribeirão Grande. Thus, the issue of housing is outstanding, while housing emerges as one of the facets of urban segregation in small towns, the result of players disinterest that have the space, especially when we talk of building joint housing for the less wealthy.
\end{abstract}

Keywords: small towns; urban segregation; housing.

1 Mestre pelo Programa de Pós-Graduação em Engenharia Urbana da Universidade Federal de São Carlos (PPGEU-UFSCar). Email: orlandomoreirajunior@yahoo.com.br. 
MOREIRA JUNIOR, O. Segregação urbana em cidades pequenas: algumas considerações...

\section{INTRODUÇÃO}

Atualmente mais de $50 \%$ da população mundial vive em áreas urbanas. Assistimos a proliferação, de forma rápida e intensa, do fato urbano pelo mundo afora. No caso brasileiro, a urbanização deu um salto considerável na última metade do século passado, com aumento do número e do tamanho das cidades. Juntamente com o que podemos chamar de revolução urbana brasileira ocorreu também uma revolução demográfica. A população urbana brasileira atingiu a taxa de 81, 25\% do total (IBGE, 2000), cuja maior característica foi o aumento do processo de metropolização. Contudo, o cenário urbano nacional é marcado pelo grande número de cidades de pequeno porte, tanto no que diz respeito a sua dimensão populacional quanto em seu tamanho físico-territorial.

Vale ressaltar que muitos estudos e pesquisas são realizados, em âmbito nacional, para se compreender as dinâmicas físico-territoriais e sociais nas metrópoles e nas cidades médias brasileiras, mas pouco estudo desta natureza tem sido realizado em cidades pequenas, que correspondem à grande maioria de sedes de municípios brasileiros, congregam um contingente expressivo da população e perfazem uma ampla extensão do território nacional.

Assim, como o fenômeno de segregação urbana se manifesta de modo mais intenso nas metrópoles e cidades de grande e médio porte, não são poucos, muito menos é escasso o interesse em investigações e pesquisas desta natureza nestes espaços urbanos. Entretanto, em função das características do momento atual, todas as cidades brasileiras exibem, com diferença de grau e de intensidade, problemáticas parecidas, pois os processos excludentes que estão em marcha não atingem apenas as cidades grandes e médias, ou seja, fenômenos como a segregação urbana vem ocorrendo independentemente do porte da cidade.

Nesta direção, o presente artigo visa refletir a respeito da segregação urbana em cidades pequenas, procurando contribuir e ampliar as discussões sobre a temática em cidades de pequeno porte. Desse modo, procuramos tecer algumas considerações a respeito do espaço que está morfologicamente em pedaços, em suas múltiplas escalas, bem como a visão da segregação urbana em cidades pequenas, considerando-se as escalas do intraurbano e do interurbano, tal qual a atuação dos atores sociais que contribuem para a produção de um espaço urbano segregado e segregador. Para tanto, traçamos uma reflexão a partir de um estudo de caso nas cidades de Capão Bonito e Ribeirão Grande, ambas localizadas na mesorregião geográfica de Itapetininga, no Estado de São Paulo.

\section{O ESPAÇO DILACERADO}

O processo de urbanização atrelado aos aspectos econômicos e à constituição de uma rede de cidades pautada na competitividade entre as cidades a fim de atender aos interesses do capitalismo produz uma avançada divisão de trabalho, em que a especialização, fragmentação, interdependência e internacionalização foram desenvolvidas em níveis sem precedentes como aponta Fernandes (2001), na qual o poder de decisão da escala local estaria sendo potencializada pela globalização, subordinados aos interesses econômicos hegemônicos. Logo, a globalização causa vigoroso impacto sobre a organização do espaço.

Neste contexto de reorganização econômica e da ocupação do território, com redefinição e articulação de diferentes escalas que reconfiguram o padrão espacial, ao mesmo tempo em que contribuem para a construção de novas interações socioespaciais representam novos desafios ao planejamento urbano e regional e as pesquisas técnico-científicas. Desse modo, as novas tendências da urbanização faz refletir a respeito da reconfiguração da rede de cidades e do papel das cidades médias e pequenas frente a inserção do país na economia globalizada.

Nesta inserção do país no mundo globalizado, atrelada ao modelo neoliberalista, as políticas governamentais passam a priorizar a inserção competitiva dos "focos dinâmicos" do país na economia mundial, como destaca Bacelar (2000). Segundo a autora ocorre no país uma "integração competitiva" que integra apenas partes do Brasil, aquelas que já apresentam certa dinâmica econômica, pois privilegia os requisitos locacionais atrelados a melhor oferta de recursos humanos qualificados, maior proximidade com centros de produção de conhecimento e tecnologia, maior e mais eficiente dotação de infraestrutura econômica, além da proximidade com os mercados consumidores de mais renda.

Do mesmo modo, é possível identificar várias áreas nas quais a urbanização se deve diretamente à consecução do agronegócio globalizado (ELIAS, 2006), ou seja, em diversas áreas do país formam-se cidades cuja função principal claramente se associa às demandas produtivas dos setores relacionados à modernização da agricultura, ratifica a autora.

Verifica-se, assim, a concretização de uma urbanização e um urbanismo fundamentado pela funcionalidade dos espaços, no qual as cidades são criadas para servir a economia e não à sociedade. Os espaços que não são funcionais à esta nova lógica sistêmica não conseguem se inserir na economia mundial, isto se ex- 
MOREIRA JUNIOR, O. Segregação urbana em cidades pequenas: algumas considerações...

pressa na dualização acelerada de suas configurações sociais, que leva a uma verdadeira separação de seus processos urbanos.

A estruturação do tecido urbano - físico e social - apresenta um caráter extremamente funcional aos interesses rentistas (FERNANDES, 2001), cujas estratégicas econômicas globais são sentidas, na concretude, na escala geográfica local e nos novos fundamentos de políticas urbanas e regionais associadas a estas transformações.

Assim, a disputa pelo uso do solo, os interesses dos atores sociais, a especulação imobiliária, a terra como reserva de valor, a divisão territorial e técnica do trabalho, dentre outros inúmeros conflitos, são responsáveis por um ordenamento territorial desigual e excludente, visível nas disputas frequentes no campo e na cidade, seja na escala local, regional ou nacional.

Nas cidades brasileiras as desigualdades e disparidades sociais e espaciais são visíveis aos olhos, sendo possível perceber a existência de bairros com infra estrutura impecável e com residências de luxo, coexistindo a curta distância, com bairros miseráveis, sem infraestrutura sanitária, com problemas ambientais graves, com serviços públicos (de saúde, educação e segurança) deficientes. Ademais, os atuais padrões de desenvolvimento tem resultado na degradação socioambiental que aflige, sobretudo, as classes de menor poder aquisitivo, como a falta de condições sanitárias mínimas em muitas áreas, destruição de recursos naturais, poluição do meio ambiente, condições precárias e insalubres de habitação, entre outros.

A urbanização brasileira ocorreu e ocorre de modo excludente, com bônus sociais para poucos, ao passo que o ônus recai sobre grande parcela dos citadinos. A lógica de ordenamento territorial de nossas cidades dá origem a uma formação socioespacial segregada e segregadora, caracterizada, principalmente por novas formas de habitats urbanos, os loteamentos fechados e os condomínios residenciais, reestruturando o espaço dos grandes centros urbanos, caracterizado, principalmente pela redefinição do par centro-periferia. Assim, verifica-se nas metrópoles tal qual nas grandes e médias cidades, a consolidação da autossegregação urbana convivendo dentro de um mesmo espaço (a cidade) com processos de segregação induzida, que "empurra" os pobres para as áreas servidas de piores serviços, equipamentos, infraestrutura urbana e de qualidade de vida. Essas novas configurações se dão como fruto das práticas, ações e estratégias dos diversos atores sociais produtores do espaço urbano, geradoras de uma estruturação urbana descontínua e segregadora.

A cidade é hoje concebida como fragmentada, há um processo de redefinição nos quadros da vida social coletiva, cuja organização territorial é marcada por enclaves territoriais descontínuos com a estrutura espacial que os rodeia, gerando separação socioespacial, sob a forma de segregação urbana. A segregação urbana é um efeito da distribuição do produto entre os sujeitos, e do produto-moradia no espaço (CASTELLS, 1983).

Villaça considera que a segregação é um aspecto fundamental para a compreensão das estruturas espaciais. É interessante observar que a segregação na cidade se impõe a nível da constituição de territórios separados para cada grupo social, refletido na forma sobre a qual se reorganiza o espaço urbano, em especial o da moradia. A exclusão e a segregação urbana têm seu início, portanto, no problema da habitação e na reprodução da moradia. Ou seria na verdade um falso problema, pois como assinala Villaça (1986), o Brasil possui exatamente o número de habitações para o qual existe uma demanda monetária. Tem-se a ideia de haver um déficit habitacional quando na verdade há um grande percentual de imóveis ociosos, ou seja, sobram imóveis desocupados e subutilizados, mas faltam moradias; um genuíno paradoxo nas cidades brasileiras. A classe dominante é então obrigada a inventar um problema que na sua lógica não existe, para depois dizer que vai resolvê-lo, ou atacá-lo (VILLAÇA, 1986).

A segregação se dá, portanto, como decorrência das condições econômicas e sociais, expressão da organização social e da produção desigual do espaço urbano, que se acentua pelo processo de (re) estruturação do espaço intraurbano, no qual verifica-se a expulsão dos pobres e a redistribuição dos ricos, por meio de uma dinâmica imobiliária dilaceradora, marcada pela segregação induzida e pela autossegregação urbana.

À medida que o espaço urbano se modifica aqueles que estão aquém do nível para entrar na lógica do solo urbano enquanto mercadoria, se veem obrigados a ocupar áreas públicas ou áreas em litígio, aglomeramse, amontoam-se, produzindo um espaço - a favela -, esse conjunto de habitações populares, toscas e com condições precárias de higiene, construídas em morros adjacentes aos grandes centros. Essa seria uma definição, porém uma definição generalista, visto que as favelas cresceram em número, em tamanho e em complexidade, pois, se a favela para muitos é um problema urbano, para tantos outros indivíduos é a solução de sobrevivência, de moradia. E mais, como muitas vezes "convivem", lado a lado, com os bairros mais luxuosos da cidade ocupam um local estratégico, pois muitos dos moradores trabalham pelas redondezas, não precisando dispor de horas e horas nos meios de transporte ruins e caros das grandes cidades. 
MOREIRA JUNIOR, O. Segregação urbana em cidades pequenas: algumas considerações...

No entanto, a favela não é a única relação que se pode traçar entre produção do espaço urbano, produção de moradia e condição de renda. Engendrada nessa relação, verifica-se em praticamente todas as cidades brasileiras o fenômeno da autoconstrução, por meio do qual as camadas mais pobres solucionam o problema da moradia, da casa própria. É comum ver, principalmente nas periferias das cidades, trabalhadores utilizando os seus dias de folga ou os fins de semana para a construção de sua habitação, como os mutirões, por exemplo. É uma solução de subsistência e não deve ser entendida, portanto, como uma economia.

Seguindo a relação entre produção do espaço urbano, produção de moradia e condição de renda, pode-se citar ainda os conjuntos habitacionais. Nestes não há o processo de autoconstrução, num primeiro momento, como nas favelas e nos bairros pobres da periferia, a moradia é construída pelo Estado. Casas pequenas, com estruturas simples, geralmente descontínuas ao tecido urbano, distante do centro da cidade, muitas vezes sem serviços, equipamentos e infraestruturas suficientes.

Os atores sociais produtores da cidade proporcionam diferentes espaços para diferentes clientelas, tanto no que tange o aspecto da moradia, resultando em espaços distintos, fragmentados espacialmente mesmo quando geograficamente próximos. Como a cidade é uma grande concentração de pessoas exercendo as mais variadas atividades, é lógico que o solo urbano seja disputado por diversos e diferentes usos, pautado nas regras do jogo capitalista. A estruturação da cidade reflete a organização social de nossa sociedade desigual, logo, é perceptível a distribuição injusta do ônus e bônus da urbanização. Como resultado desse processo, acentua-se a fragmentação, a segmentação e a segregação do espaço urbano, com a cidade continuando a se expandir de forma descontínua, tanto social quanto espacialmente.

A descontinuidade do tecido urbano é apontada por Sposito (1999) como uma das determinantes do processo de fragmentação da cidade e pode ser vista como uma das formas contemporâneas, através das quais se organiza ou se acentua a segregação socio espacial. Ademais, o problema não se estende apenas à habitação, pois os territórios que os pobres partilham são reduzidos, quando comparados às possibilidades contidas no conjunto da cidade e, proporcionalmente, tanto menores quanto maiores forem as cidades onde vivem (SPOSITO,1999). Como as políticas de implantação e lançamento dos conjuntos habitacionais e dos loteamentos populares - regulares ou não - são marcadas pelo afastamento espacial e precariedade das condições de vida urbana, os pobres são "obrigados" a conviver nas áreas mais distantes, ficando "reféns" dos territórios em que habitam. A segregação urbana, portanto, relaciona o indivíduo com o meio no qual ele está inserido, em diferentes escalas: a rua, o bairro, a cidade.

Os atores sociais responsáveis pela produção do espaço urbano é que vão fragmentar, segregar e excluir a população e os espaços. O modo como o espaço é produzido de forma desigual e seguindo interesses do capital dá origem a uma cidade partida, concretização de um espaço dilacerado em suas diversas escalas. No espaço urbano, a dilaceração do espaço se configura, principalmente, pelo caráter segregado e segregador do espaço, onde temos os pobres convivendo entre si em bairros carentes, cortiços e/ou favelas, ao mesmo tempo em que temos os ricos convivendo com seus semelhantes nos condomínios de alto padrão.

A concretização desse espaço morfologicamente em pedaços é visível nas metrópoles e cidades de porte médio, porém, a intenção aqui é avançar, especificamente, a respeito da segregação urbana em cidades pequenas no cenário atual, considerando que a problemática socioespacial destas cidades é alarmante, dado que as áreas empobrecidas dessas cidades são muito grandes, em percentuais que ultrapassam em muito os grandes centros urbanos, comparando-os com suas extensões territoriais e populacionais.

\section{OS DOIS LADOS DA SEGREGAÇÃO EM CIDADES PEQUENAS}

Ao se pensar estritamente as cidades pequenas, nos aludimos a relações mais próximas de sociabilidade entre as pessoas tal qual uma maior proximidade dos agentes políticos com a sociedade local. Hipoteticamente, o tamanho territorial das pequenas cidades permitiria uma maior proximidade entre as pessoas que vivenciam os mesmos espaços públicos: a igreja, a praça, o centro, entre outros. Contudo, as alterações das relações sociais da cidade e a fragilidade da unidade urbana não se dão apenas nas grandes e médias cidades, mas na sociedade como um todo, logo, o fenômeno de segregação urbana também se faz presente em cidades de pequeno porte.

Não são poucas as averiguações científicas da segregação urbana nas cidades de médio e grande porte, tendo como principal característica o emuralhamento da vida social ou mesmo a proliferação da cidade ilegal, como as favelas, os loteamentos irregulares e as invasões. As desigualdades e disparidades sociais 
MOREIRA JUNIOR, O. Segregação urbana em cidades pequenas: algumas considerações...

e espaciais são mais visíveis nestes núcleos urbanos. É possível perceber a existência de espaços bem servidos e bem planejados, coexistindo a curta distância com favelas, mocambos, bairros paupérrimos e precários em infraestrutura. Ademais, os atuais padrões de desenvolvimento tem resultado na degradação socio ambiental que aflige, sobretudo, as classes de menor poder aquisitivo, como a falta de condições sanitárias mínimas em muitas áreas, destruição de recursos naturais, poluição do meio ambiente, condições precárias e insalubres de habitação, entre outros.

Entretanto, vale assinalar que os problemas que se manifestam no espaço urbano nada mais são do que a expressão dos problemas da sociedade em que vivemos, altamente concentradora, de terra, renda e poder, assim, é possível verificar a manifestação da segregação urbana também em cidades pequenas, como podemos verificar nas investigações realizadas por Ferreira (2006), Bernardelli (2004) e Roma (2008), por exemplo. Nestes trabalhos podemos identificar diferentes formas de manifestação da segregação urbana em cidades pequenas, resultado das ações e práticas conflituosas dos atores que produzem o espaço urbano.

Ferreira (2006) ao estudar a segregação socioespacial em Paraguaçu Paulista, município localizado no Estado de São Paulo, com cerca de 36.625 habitantes urbanos conforme o censo de 2000 , identificou a existência de quatro favelas dentro do espaço intraurbano. Ressalte-se que a favelização é a forma mais clara de segregação socioespacial da população de menor poder aquisitivo. Por um lado, a segregação se confirma em cidades pequenas em seu caráter espacial, devido à distância do centro da cidade e as dificuldades de mobilidade para se deslocarem até o mesmo como verificou Ferreira (2006). Confirma-se, num primeiro momento, a ideia de Villaça (2003), para o qual a segregação urbana atua através da acessibilidade, ou seja, através das facilidades ou dificuldades de locomoção no espaço urbano. Por outro lado, a segregação urbana se reflete em seu caráter social, pois os favelados vivem à margem da cidade, uma vez que suas relações se limitavam à área das favelas e, além disso, sofriam preconceito (FERREIRA, 2006). Há, nitidamente, aquilo que Kowarick (2000) denomina de "estigmatização do status de cidadão enquanto morador urbano", que constrói uma leitura do cortiço e da favela como germes de moralidade duvidosa e foco de transgressão, ratifica o autor.

Este estudo revela que mesmo com o processo de desfavelização viabilizado pela ação pública de transferência da população para um conjunto habitacional, a condição de assentados não garantiu a superação da segregação, pois, conforme o exposto por Ferreira
(2006), ocorre no imaginário urbano uma estigmatização da área do conjunto habitacional, visto como o conjunto habitacional dos favelados.

Sob o aspecto da reprodução social do espaço urbano e da produção da moradia, Bernardelli (2004) assinala que a moradia implementada através dos conjuntos habitacionais financiados com recursos públicos é uma das formas mais marcantes de (re) produção do espaço, marcada pela incorporação de áreas geralmente extensas e por transformação extremamente rápida da paisagem urbana. Bernardelli não faz uma análise focada na segregação, no entanto, é perceptível sua manifestação devido, sobretudo, a acessibilidade, pois é considerável a distância dos conjuntos habitacionais em relação a área central da cidade onde estão localizadas toda estrutura comercial e de serviços.

Conforme Bernardelli (2004) é muito significativa a participação do Estado na produção de moradias e outras políticas que se destinam à reprodução da força de trabalho voltadas à sustentação agroindustrial. Destarte, a moradia é vista, em sua análise enquanto processo de reprodução social, no qual o Estado apresenta papel fundamental na reprodução do espaço urbano.

Já, a investigação desenvolvida por Roma (2008), centra-se em identificar como o processo de segregação socioespacial se estrutura no contexto das cidades pequenas, efetuando uma análise empírica em duas cidades paulistas: Osvaldo Cruz e Mariápolis. A primeira com população urbana de 26.141 habitantes e a segunda com 2.813 habitantes urbanos. Em Osvaldo Cruz, Roma (2008) aponta a existência de dois loteamentos fechados e de uma favela, além de um loteamento com presença dos piores indicadores de condição de vida urbana expressando uma desigualdade socioespacial intraurbana (ROMA, 2008). Desse modo, verifica a concretização da segregação socioespacial enquanto resultado da produção desigual do espaço urbano. Entretanto, a análise realizada por Roma (2008) avança, propondo pensar a segregação para além do espaço intraurbano, ao passo que devido a funções urbanas deficientes, a população de Mariápolis necessita se deslocar para Adamantina para suprir suas necessidades básicas e aponta que essa população não se sente inserida em uma realidade urbana. Ressalte-se que novamente a acessibilidade emerge como fator preponderante para a designação da segregação e que, ao se pensar numa segregação socioespacial interurbana o fator espacial deve ser ressaltado, pois a distância entre as cidades (no caso Mariápolis e Adamantina) deve ser considerada adquirindo relevante importância na análise.

Nesta direção é que procuraremos apresentar uma reflexão da segregação (inter) urbana em Capão 
MOREIRA JUNIOR, O. Segregação urbana em cidades pequenas: algumas considerações...

Bonito e Ribeirão Grande (figura 1). Consoante dados do censo do IBGE de 2000, Capão Bonito apresenta uma população de 46.732 residentes, dos quais cerca de $78 \%$ correspondente a população urbana, enquanto
Ribeirão Grande apresenta uma população de 7.390 , dos quais 2.325 correspondem a população urbana, ou seja, cerca de $31 \%$ do total.

Como a produção do espaço urbano não só re-

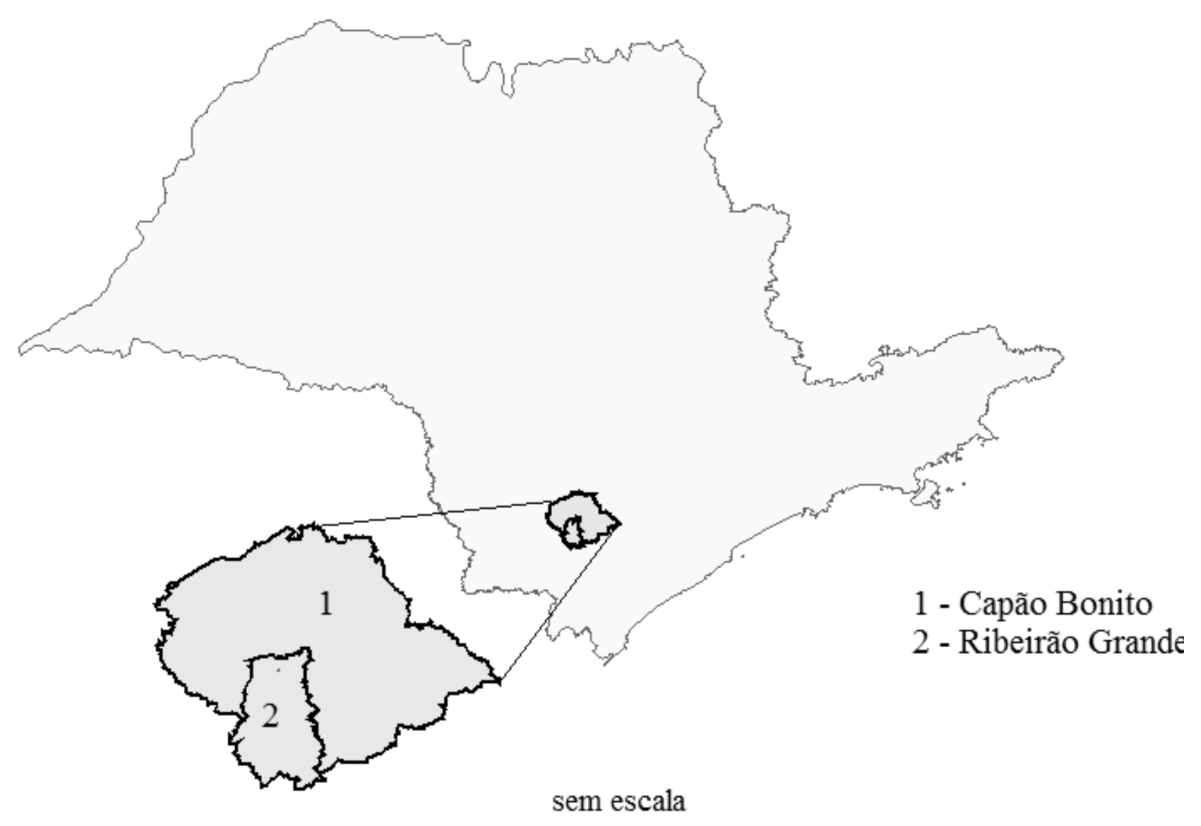

FIGURA 1 - LOCALIZAÇÃO DOS MUNICÍPIOS DE CAPÃO BONITO E RIBEIRÃO GRANDE NO ESTADO DE SÃO PAULO

FONTE: Elaborado a partir de informações do Geosnic Org.: Orlando Moreira Junior, 2009.

flete as desigualdades e as contradições sociais, como também as reafirma e reproduz, cabe, portanto, discutirmos aqui o modo como se deu e se dá a produção espacial e de habitação popular em Capão Bonito e Ribeirão Grande, identificando mais que as desigualdades existentes entre as diferentes partes das cidades, a atuação dos atores produtores do espaço urbano na esfera política que contribuem para intensificar a segregação urbana.

O primeiro desafio com que nos deparamos é de articular as relações entre as escalas intra e interurbana, tal qual as relações entre o rural, o agrícola e o urbano, pois essas inter-relações possibilitam-nos compreender o espaço intraurbano de forma mais ampla. Os processos excludentes em cidades pequenas é decorrente de uma série de processos de ordem econômica, política e social que excluem uma parcela da população para incluir novamente, mesmo que de forma precária. Processos que se sucedem e que se configuram a partir da exclusão do mercado legal de terras, na expulsão do campo, na ausência de infraestruturas e serviços, na falta de empregos, na ausência de representatividade política por parte da população e ausência de movimentos sociais urbanos organizados, que vão, cada um a sua medida, refletir na concretização da segregação intra e interurbana.

Do ponto de vista da segregação no espaço intraurbano, em Capão Bonito não há processo de emuralhamento da vida social por meio da construção de loteamentos fechados. A segregação mais visível aos olhos é a segregação induzida, muito influenciada pelas ações do poder público, principalmente pela construção de conjuntos habitacionais. Ressalte-se que em Capão Bonito, esses empreendimentos habitacionais têm papel primordial na produção do espaço urbano, totalizando 335 unidades habitacionais, entre as já entregues e as com previsão de entrega, segundo informações da Secretaria de Habitação do Estado de São Paulo. A figura 2 apresenta a localização dos conjuntos habitacionais Jardim Helena, Jardim da Amizade, Jardim São Francisco de Assis, Jardim Vale Verde e Vila Boa Esperança 


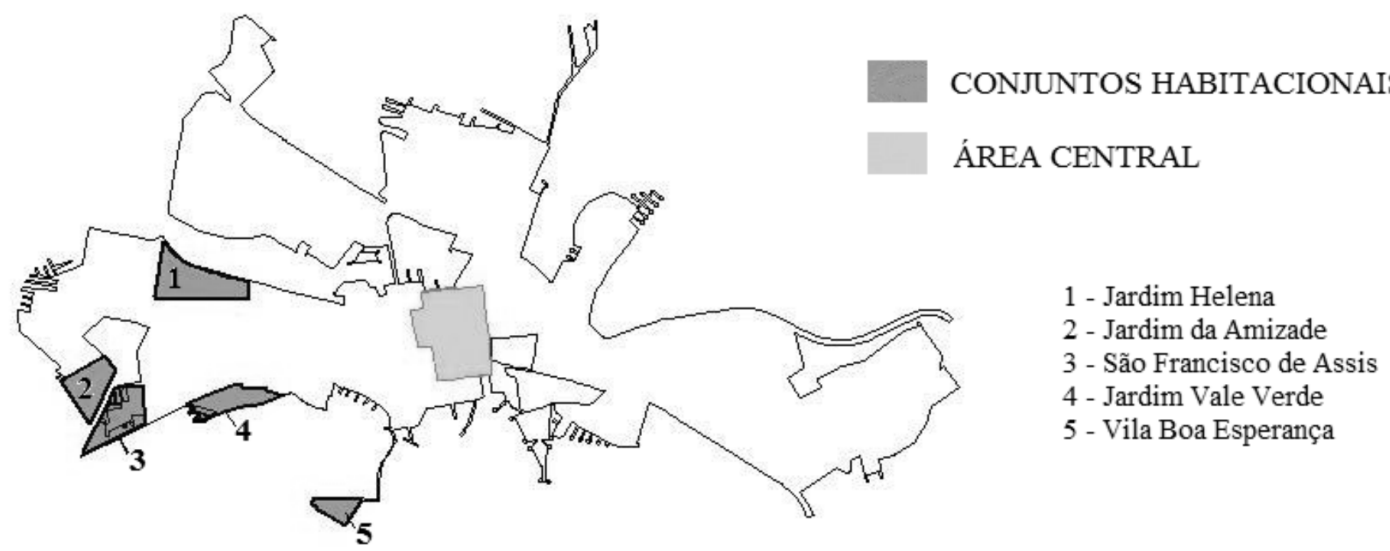

sem escala

FIGURA 2 - LOCALIZAÇÃO DOS CONJUNTOS HABITACIONAIS NA CIDADE DE CAPÃO BONITO

FONTE: Prefeitura Municipal de Capão Bonito.

Org.: Orlando Moreira Junior, 2009.

no espaço intraurbano capão-bonitense.

Importante salientar que a habitação urbana vai além dos números e das unidades residenciais, devendo estar conectada às redes de infraestrutura (água, esgoto, energia elétrica, drenagem pluvial, pavimentação) e ter o apoio dos serviços urbanos (transporte coletivo, coleta de lixo, educação, saúde, abastecimento, etc.) como aponta Maricato (1997). Nesta direção, dois pontos merecem destaque, o primeiro é referente à acessibilidade, fundamental para a consolidação do direito à cidade, pois os conjuntos habitacionais localizam-se às margens da cidade, distantes do centro comercial e administrativo, como pode ser verificado na figura 2 .

O acesso não é restrito ao conjunto da cidade apenas, mas também refere-se à distribuição de bens, serviços e infraestruturas que ainda são insuficientes ou ausentes nessas localidades, ou seja, a segregação se acentua na forma de ocupação do solo e na distribuição das engenharias urbanas. O segundo ponto é a impessoalidade das habitações, que nem sempre atendem a demanda das famílias, ademais a qualidade arquitetônica muito deixa a desejar, influenciando aí na habitabilidade das moradias. Vale destacar que no decorrer dos anos os moradores vão modificando, geralmente pelo sistema de autoconstrução, as características das casas, dando-lhes algumas características peculiares.

Ademais, verifica-se que algumas áreas, muitas vezes, recebem apenas a infraestrutura básica (asfalto, rede de água, rede de esgoto, rede de luz), outras nem isso, sendo que, em sua ampla maioria, não são beneficiadas com outros investimentos e equipamentos urbanos como escolas, creches, postos de saúde, áreas e equipamentos de lazer.

O caso mais extremo é o do Jardim Boa Esperança, construído em descontinuidade com o tecido urbano, como mostra a figura 2. Além de distante, de difícil acesso pela ausência de transporte coletivo, e ausência de infraestruturas e equipamentos urbanos, a situação se agrava pela precariedade das habitações do conjunto (figura 3). A deterioração das casas (em madeira) e tantos outros entraves enfrentados no cotidiano dos moradores deste conjunto habitacional revelam o descaso e abandono dessa população pelos governantes locais. E a continuidade nas obras, agora em alvenaria (figura 4), nos coloca uma questão: a intenção é relocar os atuais moradores ou as novas habitações servirão a 


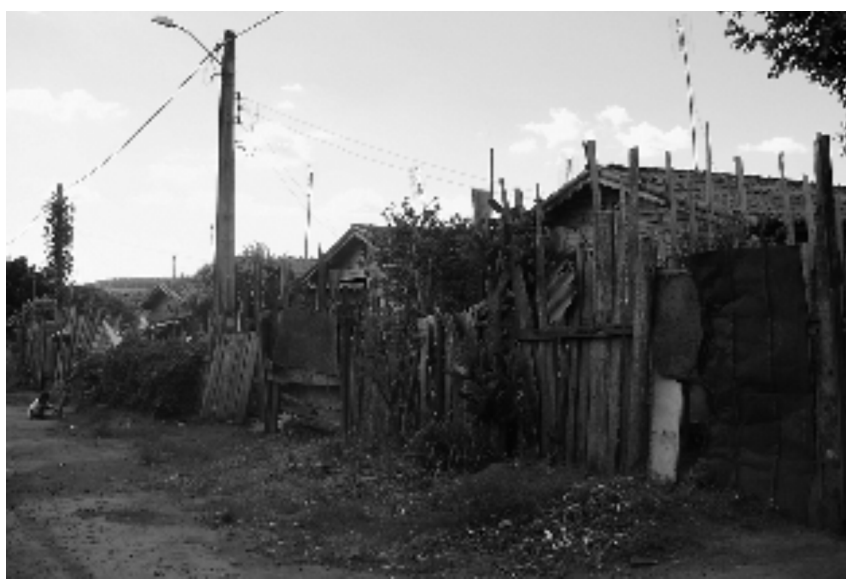

FIGURA 3 - JARDIM BOA ESPERANÇA

FONTE: Orlando Moreira Junior, trabalho em campo, 2009

futuros "beneficiados"?

A partir do exposto podemos auferir duas breves considerações, principalmente se nos voltarmos para o momento atual em que as discussões a respeito de habitação de interesse social ganha espaço no discurso político e acadêmico. Primeiramente, fica a indagação se esse tipo de habitação de interesse social seria uma ação focada na efetiva inclusão urbana?; e, em segundo lugar, de defendermos a ideia de que não se trata de estar incluído nos registros de propriedade apenas, mas sim nas oportunidades que a vida na cidade significa.

Quanto à cidade de Ribeirão Grande, cujo tamanho físico-territorial e populacional é bem mais reduzido, a segregação intraurbana se expressa, principalmente pela distância entre as áreas mais periféricas do centro, bem como as dificuldades de acesso devido ao relevo acidentado onde se assenta a malha urbana, e como não há transporte intraurbano as distâncias tornam-se ainda maiores para as crianças pequenas, grávidas, idosos e deficientes. No entanto, a medida da segregação que tem maior peso para Ribeirão Grande é a interurbana. Como apresenta um centro comercial bastante restrito e deficiências em serviços elementares como saúde por exemplo, a dependência em relação à Capão Bonito é muito grande, notável nos movimentos pendulares diários entre as duas cidades, logo, os processos ocorridos em Ribeirão Grande não podem ser considerados somente no âmbito intraurbano, uma vez que o essencial para a vida urbana só pode ser suprido a partir de relações interurbanas, visto que se apresenta, analogicamente, como uma periferia de Capão Bonito. A figura 5 representa um esquema das cidades estudadas

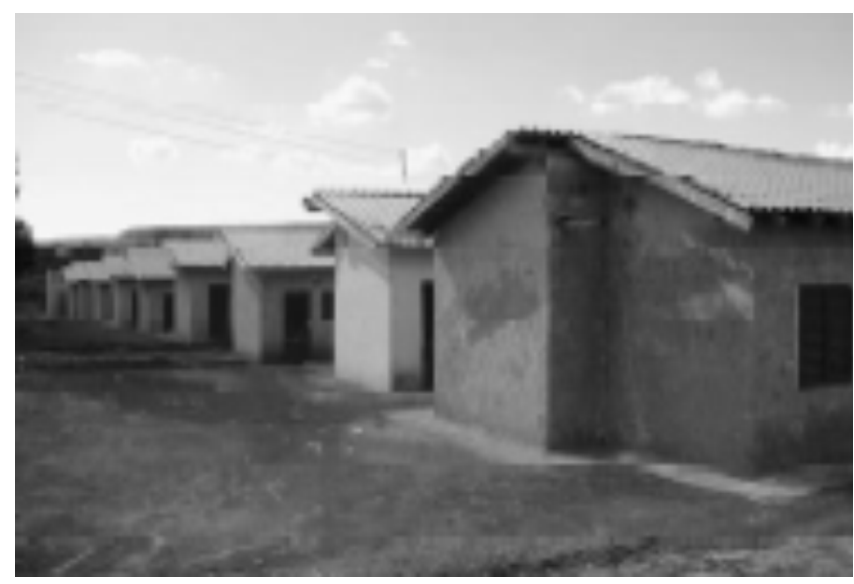

FIGURA 4 - NOVAS CONSTRUÇÕES DO JARDIM BOA ESPERANÇA

FONTE: Orlando Moreira Junior, trabalho em campo, 2009

inseridas na rede urbana, com suas interligações por meio das vias de circulação, no caso as rodovias. Por meio deste é possível averiguar a proximidade entre Capão Bonito e Ribeirão Grande, fator determinante para que a dependência de uma em relação a outra se concretize.

Como assinalamos anteriormente, o momento atual é marcado pela fragmentação espacial nas mais diversas escalas, por isso a posição de uma cidade na rede de cidades, sua distância e falta de acessibilidade a cidades mais equipadas, especialmente se ela não tem todos os meios de consumo coletivos, pode ampliar e tornar ainda pior a segregação socioespacial e a exclusão de seus habitantes (BERNARDELLI, 2004). O processo contemporâneo de produção de espaço mescla uns poucos ganhadores grandes com muitos perdedores pequenos como afirma Gottdiener (1997), isso em diversas escalas, expresso pelos dois lados da segregação nas cidades pequenas - a segregação intra e interurbana. Ademais, a problemática habitacional já não pode ser discutida e pensada apenas em metrópoles e cidades grandes e médias, ela já se faz sentir nas cidades pequenas, seja pelo processo de favelização (como nos trabalhos de Ferreira (2006) ou Roma (2008)), seja na precariedade dos conjuntos habitacionais, como nos esforçamos para apresentar aqui, ou ainda pelas invasões frequentes de áreas públicas ou impróprias para urbanização e proliferação de loteamentos clandestinos, cada vez mais presentes no processo de produção espacial em cidades de pequeno porte. 
MOREIRA JUNIOR, O. Segregação urbana em cidades pequenas: algumas considerações...
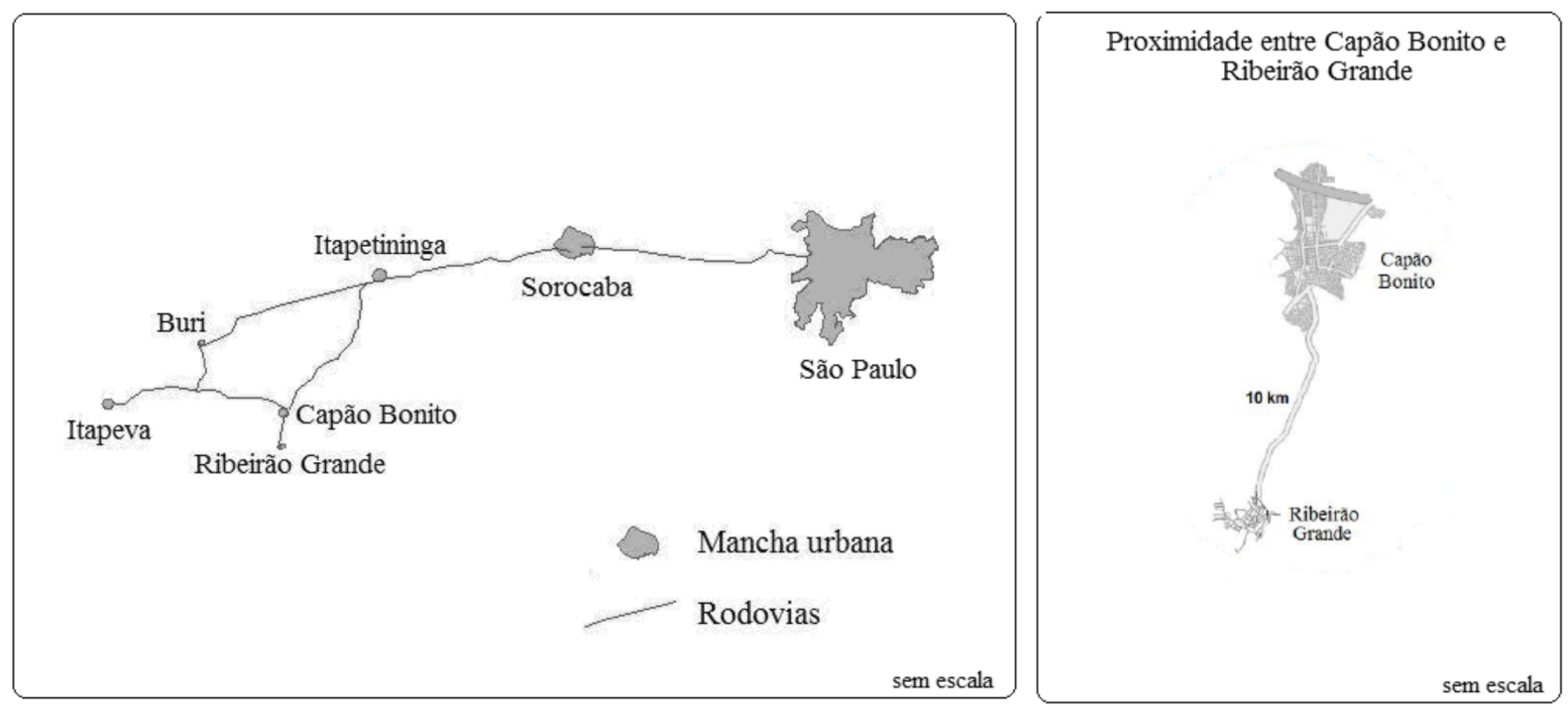

FIGURA 5 - CROQUI DAS CIDADES ESTUDADAS NA REDE URBANA E INTERLIGAÇÃO ENTRE AS DUAS CIDADES

FONTE: Elaborado a partir de informações do Geosnic e do Google Maps Org.: Orlando Moreira Junior, 2009.

\section{CONSIDERAÇÕES FINAIS}

Santos (1988) já assinalava que a localização das pessoas no território é na maioria das vezes, produto de uma combinação de forças de mercado e decisões de governo. Se pensarmos a cidade atual como mercadoria e a própria mercantilização do espaço em suas múltiplas escalas, concluímos que a segregação é a forma de exclusão que se manifesta em sua dimensão espacial, na qual o mecanismo de mercado e também o poder público produzem um espaço onde os pobres ficam com as piores localizações como coloca Villaça (2003).

A dramaticidade da exclusão social de modo geral e da segregação socioespacial em particular é proveniente, em certa medida, da precária relação entre as ações e práticas governamentais - federal, estadual e municipal - e a preocupação com a problemática social do país, visto que apesar dos planos, políticas e normas prezarem pela inclusão e por uma cidade mais justa, ela não enxerga a injustiça e exclusões que permeiam o fato urbano destas realidades. Os problemas habitacionais devem ser considerados como parte central das políticas fundiárias, urbanas e regionais (CASTRO, 2000), visto que o direito à cidade passa pelo acesso a condição digna de habitação legal e do acesso ao conjunto de benefícios que a cidade tem a oferecer, indiferente do seu porte territorial ou populacional.

Os processos excludentes se acirram cada vez mais no interior dos espaços urbanos e no caso das pequenas cidades pode ser ainda mais cruel. Junta-se a isso a necessidade de soluções de planejamento urbano e regional próprios para os casos das cidades pequenas, neste período de construção de novas interações socioespaciais em diversas escalas que influenciam na produção desigual, excludente e segregadora do espaço urbano. Ocorre uma dilaceração do espaço, marcado pela funcionalidade dos locais e pela competição entre as cidades. O espaço é marcado pela sua fragmentação seja na escala intraurbana ou regional, o que aumenta a diferenciação na lógica de organização espacial, na qual denota-se seletividade de distribuição das políticas públicas, reforçando-se as diferenças, cada vez mais complexas e dilaceradoras. 
MOREIRA JUNIOR, O. Segregação urbana em cidades pequenas: algumas considerações...

\section{REFERÊNCIAS}

BACELAR, T. Dinâmica regional brasileira nos anos noventa: rumo à desintegração competitiva? In: CASTRO, Iná Eias de; MIRANDA, Mariana; EGLER, Cláudio A. G. (Orgs). Redescobrindo o Brasil: 500 anos depois. Rio de Janeiro: Bertrand Brasil: FAPERJ, 2000. p. 73-91.

BERNARDELLI, M. L. F. H. Pequenas cidades na região de Catanduva - SP: papéis urbanos, reprodução social e produção de moradias. 347f. Tese (Doutorado em Geografia) - FCT/ UNESP, Presidente Prudente. 2004.

CASTELLS, M. A questão urbana. Rio de Janeiro: Paz e Terra, 1983.

CASTRO, C. M. P. O Estatuto da Cidade e Ampliação do Acesso à Moradia. In: BRAGA, R.; CARVALHO, P. F. (Orgs.) Estatuto da Cidade: política urbana e cidadania. Rio Claro: Laboratório de Planejamento Municipal - Deplan - UNESP _ IGCE, 2000. p. 31-40.

ELIAS, D. Globalização e fragmentação do espaço agrícola do Brasil. Scripta Nova - Revista electrónica de geografía y ciencias sociales. Barcelona: Universidad de Barcelona, v.X, n. 218, ago/2006. Disponível em: <http://www.ub.es/geocrit/ sn/sn-218-03.htm>.

FERNANDES, A. C. Da reestruturação corporativa à competição entre cidades: lições urbanas sobre os ajustes de interesses globais e locais no capitalismo contemporâneo. Espaço \& Debates, São Paulo: NERU, ano 17, n.41, p. 415 - 435, 2001.

FERREIRA, E. A segregação socioespacial no município de Paraguaçu Paulista - SP: da favela ao conjunto habitacional. Monografia (Bacharelado em Geografia) - FCT/UNESP, Presidente Prudente. 2006.

GEOSNIC: banco de dados. Disponível em: <http://geosnic. cidades.gov.br/src/php/app.php> Acesso em fev. de 2009.

GOTTDIENER, M. A produção social do espaço urbano. São Paulo: Editora da Universidade de São Paulo, 1997.

IBGE. Censo Demográfico. Brasília, 2000.

KOWARICK, L. Escritos urbanos. São Paulo: Ed. 34, 2000.

MARICATO, E. Habitação e cidade. São Paulo: Atual, 1997.

ROMA, C. M. Segregação sócio-espacial em cidades pequenas. 156f. Dissertação (Mestrado em Geografia) - FCT/ UNESP, Presidente Prudente, 2008.

SANTOS, M. Metamorfoses do espaço habitado. São Paulo: Hucitec, 1988.

SÃO PAULO. Secretaria de Habitação do Estado de São Paulo. Disponível em: <http://www.habitacao.sp.gov.br> Acesso em jun. de 2009.

SPOSITO, M. E. B. Espaços urbanos: territorialidades e representações. In: SPOSITO, E. S. (Org). Dinâmica econômica, poder e novas territorialidades. Presidente Prudente: UNESP/FCT: GAsPERR, 1999. p. 13 - 29.

VILLAÇA, F. O que todo cidadão precisa saber sobre habitação. São Paulo: Global, 1986.

VILLAÇA, F. A segregação urbana e a justiça (ou a justiça no injusto espaço urbano). Revista Brasileira de Ciências Criminais, ano 11, n.44, p. 241-346, jul/set 2003.

\section{AGRADECIMENTOS}

À Fundação de Amparo à Pesquisa do Estado de São Paulo (FAPESP) pelo apoio recebido. 